\title{
12 PERFIL MOTIVACIONAL E DEMOGRÁFICO DOS ALUNOS DO MESTRADO ACADÊMICO E PROFISSIONAL ${ }^{1}$
}

\author{
| Rejane Ferreira²; Claudia Tavares ${ }^{3}$; Gabriela dos Santos'; Letycia Manhães ${ }^{5}$; Fernanda Marcondes ${ }^{6}$; Taísa Felippe ${ }^{7}$ |
}

\section{RESUMO}

CONTEXTO: O curso de mestrado em enfermagem tem contribuido para o avanço da profissão ao longo dos seus 40 anos, devido à alta produção científica.

OBJETIVO: Conhecer o perfil dos alunos de mestrado acadêmico e profissional do estado do Rio de Janeiro, e suas motivações para realizar o mestrado.

METODOLOGIA: Pesquisa quantitativa, baseada em dados primários obtidos através da aplicação de questionário sociodemográfico aos alunos regulares matriculados nos programas de mestrado em enfermagem das universidades públicas do estado do Rio de Janeiro.

RESULTADOS: Verificou-se que os alunos mais jovens de idade e de profissão optam pelo mestrado acadêmico, enquanto que o oposto opta pelo mestrado profissional. A motivação dos alunos esta ligada a busca de novos conhecimentos e qualificação para melhorar a atuação tanto na prática assistêncial, quanto na docência em saúde. Foi constatado que o incentivo precoce às atividades acadêmicas durante a graduação contribui positivamente na motivação do aluno para ingressar no mestrado.

CONCLUSÕES: O perfil e as motivações que levam os alunos a ingressarem nas duas modalidades de mestrado - acadêmico e profissional, são bem características e encontram correspondência com a proposta de cada curso.

\section{PALAVRAS-CHAVE: Educação de pós-graduação em enfermagem; Motivação; Enfermeiras}

\section{RESUMEN}

“Perfil motivacional y demográfico del estudiante de master académico y professional"

CONTEXTO: El Máster en enfermería ha contribuido al avance de la profesión a lo largo de sus 40 años, debido a la intensa producción científica.

OBJETIVO: Conocer el perfil de los estudiantes de máster académico y profesional en el estado de Río de Janeiro, y sus motivaciones para ingresar en dichos másters.

METODOLOGÍA: La investigación cuantitativa, basada en datos primarios obtenidos mediante la aplicación del cuestionario socio demográfico de los estudiantes regulares inscritos en programas de máster en enfermería en las universidades públicas en el estado de Río de Janeiro.

RESULTADOS: Se concluyó que los estudiantes más jóvenes y con menor experiencia profesional eligen el máster académico, mientras que lo contrario opta por el máster profesional. La motivación de los estudiantes está vinculada a la búsqueda de nuevos conocimientos y habilidades para mejorar el rendimiento tanto en la práctica de atención, como la enseñanza de la salud. Se ha encontrado que los principios de fomento de las actividades académicas durante la graduación contribuyen positivamente a la motivación del estudiante para participar en los másteres.

CONCLUSIONES: El perfil y los motivos que llevan a los estudiantes a frecuentar los dos tipos de maestro - académico y profesional, son muy característicos y se hacen coincidir con la propuesta de cada curso.

\section{DESCRIPTORES: Educación Graduado en Enfermería; Moti- vación; Enfermeras}

\begin{abstract}
"Motivational and demographical profile of academic and professional master students"

BACKGROUND: The Master's degree in nursing has contributed to the advancement of the profession throughout its 40 years, due to the high amount of scientific production.

OBJECTIVE: Getting to know the profile of academic and professional master's students in the state of Rio de Janeiro, and their motivations for taking the Master.

METHODS: Quantitative research, based on primary data obtained through the application of sociodemographic questionnaire to regular students enrolled in master's programs in nursing of public universities in the state of Rio de Janeiro.

RESULTS: It was found that younger students and with less professional experience choose the academic master, while the opposite opt for a professional master. The students' motivation is linked to the quest for knowledge and skills to improve performance both in the care practice, and in the health teaching. It has been found that early encouragement of academic activities during graduation contributes positively to the student's motivation to enrol for the Masters.

CONCLUSIONS: The profile and the motivations that lead students to join the two types of master - academic and professional, are very characteristic and match with the proposal of each course.
\end{abstract}

\section{KEYWORDS: Education, nursing, graduate; Motivation; Nurses}

Submetido em 18-04-2016

Aceite em 17-06-2016

1 Este artigo foi extraído da dissertação intitulada "A motivação do enfermeiro para a realização do mestrado e sua relação com o desenvolvimento profissional”, 2015.

2 Enfermeira; Doutoranda em Ciências do Cuidado em Saúde na Universidade Federal Fluminense, Niterói, RJ, Brasil, rejane_eleuterio@hotmail.com

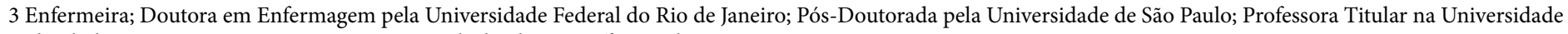
Federal Fluminense, 24020-091 Niterói, RJ, Brasil, claudiamarauff@gmail.com

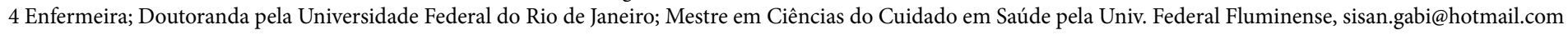

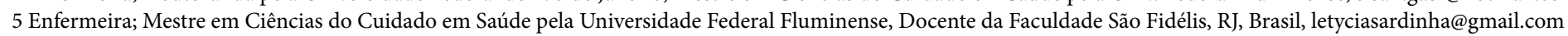
6 Enfermeira; Mestre em Ciências do Cuidado em Saúde pela Universidade Federal Fluminense, Niterói, RJ, Brasil, fe_laxe@yahoo.com.br

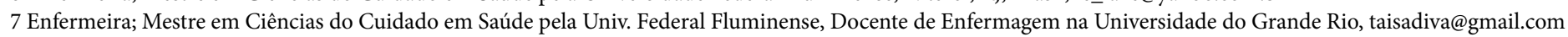

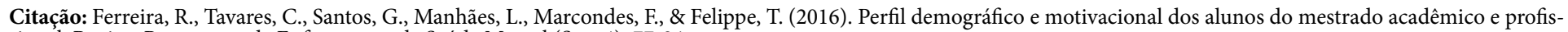
sional. Revista Portuguesa de Enfermagem de Saúde Mental (Spe. 4), 77-84. 


\section{INTRODUÇÃO}

A pós-graduação stricto sensu é de natureza acadêmica e de pesquisa, compreende programas de mestrado e doutorado com obtenção de diploma na conclusão do curso (Parecer no 977/65). Os cursos stricto sensu objetivam a produção de dissertações e teses que formulem e comprovem teorias novas para o entendimento de fatos e de suas relações (Lei $n^{\circ}$ 9394/96).

Na América Latina a pós-graduação Stricto Sensu em enfermagem surgiu em 1969 com a criação dos primeiros mestrados acadêmicos na Venezuela e Colômbia (Scochi et al., 2013). Com intuito de qualificar enfermeiros para sua inserção no mercado de trabalho, em instituições de ensino, de pesquisa ou de prestação direta de serviços, iniciou no Brasil em 1972, o primeiro mestrado em enfermagem fundamental, na Escola de Enfermagem Anna Nery (EEAN), da Universidade Federal do Rio de Janeiro (UFRJ). O doutorado surgiu na década seguinte na Escola de Enfermagem da Universidade de São Paulo (EEUSP) em parceria com a Escola de Enfermagem de Ribeirão Preto (Erdmann, Fernandes, e Teixeira, 2011). O primeiro curso de mestrado profissional em enfermagem, teve início em 2004, na Escola de Enfermagem Aurora Afonso Costa (EEAAC), da Universidade Federal Fluminense (UFF) (Silvino, 2013).

Os programas de pós-graduação stricto sensu em enfermagem no Brasil no auge dos seus 40 anos permanecem em expansão. $\mathrm{O}$ impacto desse progresso pode ser percebido no aumento gradual de cursos e na titulação de mestres e doutores, comparados nos últimos anos, assim como o crescimento das produções científicas indexados nas bases de dados nacionais e internacionais (Monteiro et al., 2012).

Os avanços da pesquisa científica vêm sendo concretizados quase que totalmente nos espaços ou ambientes onde se efetivam os cursos de mestrado acadêmico, mestrado profissional e doutorado. Estes são produzidos em meio às atividades acadêmicas, centradas nos grupos de pesquisa, que integram alunos de todos os níveis de formação, da graduação ao estágio pós-doutoral, com vínculos e procedências diversas (Scochi et al., 2013).

Pesquisa realizada por Monteiro et al. (2012), mostra que a motivação para cursar uma pós graduação stricto sensu deve começar ainda na graduação. Segundo ele, os enfermeiros que receberam, no decorrer da graduação, incentivos para a pesquisa, sendo bolsistas ou voluntários, tendo participado de monitoria e projetos extensionistas, com identificação de situações problemas e objeto de estudo a serem investigados, são os que apresentam maior motivação para fazer a pós-graduação stricto sensu. Em contrapartida, o desconhecimento ou conhecimento limitado dos programas são fatores desmotivadores do interesse em investimento na formação continuada. Na enfermagem, a pós-graduação strictosensu além de contribuir com a qualificação dos profissionais para atuar na assistência em saúde e docência, colabora com a construção de novos conhecimentos e com a ampliação do horizonte profissional, pessoal e social do enfermeiro (Ferreira e Tavares, 2015).

As questões referentes à motivação para o profissional investir em sua formação devem ser bem estudadas, pois a sociedade precisa de profissionais qualificados e atualizados. Vale ressaltar que o mestrado é o primeiro acesso do enfermeiro ao curso de pós-graduação stricto sensu, e também é o curso que antecede o doutorado . Sendo assim, o estudo tem como objetivo conhecer o perfil dos alunos de mestrado acadêmico e profissional do estado do Rio de Janeiro, e suas motivações para realizar o mestrado.

\section{METODOLOGIA}

Trata-se de uma investigação do tipo exploratória, de abordagem quantitativa, baseada em dados primários obtidos através da aplicação de questionário sociodemográfico, no mês de junho de 2014, aos alunos matriculados em três programas de Mestrado Profissional (MP) e quatro programas de Mestrado Acadêmico (MA) de escolas de enfermagem das universidades públicas do estado do Rio de Janeiro.

Os sujeitos deste estudo foram os enfermeiros que cursam o mestrado nas quatro universidades públicas selecionadas. Como critério de inclusão no estudo estabeleceu-se: enfermeiros matriculados no curso de mestrado, que estivesse cursando entre o $1^{\circ}$ ao $4^{\circ}$ semestre, matriculados nas disciplinas obrigatórias no primeiro semestre de 2014. E como critério de exclusão: alunos com matrícula trancada, alunos ouvintes e profissionais não enfermeiro. $\mathrm{O}$ tamanho da população do estudo era $\mathrm{N}=340$, sendo necessário um tamanho amostral ideal com erro amostral de $\mathrm{N}=150$, erro máximo admitido cometer, de 0,08 (8\%) com 95\% de confiança. Baseando-se na amostragem aleatória estratificada por tipo de mestrado, ou seja, pelo total de alunos em cada programa de mestrado (acadêmico e profissional), o tamanho amostral ideal com erro amostral foi $\mathrm{N}=101$ no mestrado acadêmico e $\mathrm{N}=49$ no mestrado profissional. Foram aplicados 176 questionários: 126 nos alunos do (MA) e 50 nos alunos do (MP), superando a amostragem estatística para cada modalidade de mestrado. 
Todos os questionários foram aproveitados. Os dados foram organizados em um banco de dados produzidos no Microsoft Office Excel 2007, processados e analisados de forma descritiva e de acordo com a literatura pertinente. As análises foram feitas no programa estatístico BioStat 5.3, utilizando o Teste Qui-quadrado de tendência linear, ao nível de significância estatística de $5 \%(p \leq 0.05)$. Os resultados foram descritos e apresentados em forma de tabelas.

A pesquisa foi aprovada pelo Comitê de Ética e Pesquisa sob o n ${ }^{\circ} 695.428$.

\section{RESULTADOS}

\section{Perfil Demográfico}

O perfil dos alunos dos dois mestrados em enfermagem caracteriza-se por uma população em sua maioria do gênero feminino (85\%) e que se declararam de característica étnico-racial branca (56\%). Os enfermeiros solteiros mais jovens são alunos do mestrado acadêmico (MA), enquanto que os mais velhos e casados são do mestrado profissional (MP) (Tabela 1).

Tabela 1 - Características Demográficas dos Enfermeiros que Cursam o Mestrado em Enfermagem. Brasil, 2015. ( $\mathrm{N}=150)$

\begin{tabular}{|c|c|c|c|}
\hline \multicolumn{4}{|c|}{ DADOS PESSOAIS } \\
\hline \multicolumn{2}{|c|}{ Mestrado Acadêmico (MA) } & \multicolumn{2}{|c|}{ Mestrado Profissional (MP) } \\
\hline \multicolumn{2}{|c|}{ SEXO } & \multicolumn{2}{|c|}{ SEXO } \\
\hline Feminino & Masculino & Feminino & Masculino \\
\hline $106(72 \%)$ & $20(28 \%)$ & $44(88 \%)$ & $6(12 \%)$ \\
\hline \multicolumn{2}{|c|}{ IDADE } & \multicolumn{2}{|c|}{ IDADE } \\
\hline \multicolumn{2}{|c|}{25 a 30 anos } & \multicolumn{2}{|c|}{35 a 40 anos } \\
\hline \multicolumn{2}{|c|}{$\begin{array}{l}\text { CARACTERÍSTICAS ÉTNICO- } \\
\text { RACIAIS }\end{array}$} & \multicolumn{2}{|c|}{$\begin{array}{l}\text { CARACTERÍSTICAS ÉTNICO- } \\
\text { RACIAIS }\end{array}$} \\
\hline Branco & $70(56 \%)$ & Branco & $28(56 \%)$ \\
\hline Negro & $10(8 \%)$ & Negro & $3(6 \%)$ \\
\hline Pardo & $44(35 \%)$ & Pardo & $19(38 \%)$ \\
\hline Não respondeu & $2(1 \%)$ & Não respondeu & - \\
\hline \multicolumn{2}{|c|}{ ESTADO CIVIL } & \multicolumn{2}{|c|}{ ESTADO CIVIL } \\
\hline Solteiro & $73(58 \%)$ & Solteiro & $18(36 \%)$ \\
\hline Casado & $40(31 \%)$ & Casado & $17(34 \%)$ \\
\hline Divorciado & $6(5 \%)$ & Divorciado & $7(14 \%)$ \\
\hline Desquitado & $1(1 \%)$ & Desquitado & $1(2 \%)$ \\
\hline Viúvo & $1(1 \%)$ & Viúvo & $2(4 \%)$ \\
\hline União Estável & $4(3 \%)$ & União Estável & $3(6 \%)$ \\
\hline Não respondeu & $1(1 \%)$ & Não respondeu & $2(4 \%)$ \\
\hline \multicolumn{2}{|c|}{ FILHOS } & \multicolumn{2}{|c|}{ FILHOS } \\
\hline Sim & Não & Sim & Não \\
\hline $23(82 \%)$ & $103(18 \%)$ & $28(56 \%)$ & $22(44 \%)$ \\
\hline \multicolumn{2}{|c|}{ Total: 126} & \multicolumn{2}{|c|}{ Total: 50} \\
\hline
\end{tabular}

Características da Formação dos Alunos do Mestrado em Enfermagem

Quanto à formação verificou-se que 3\% dos alunos do MA concluiu mais de um curso de graduação, a maioria (64\%) tem até cinco anos de formação, 81\% concluiu um ou mais cursos de especialização e que mais da metade (55\%) já foram alunos da instituição onde estão realizando o mestrado, sendo a UFF a instituição que mais tem ex-alunos cursando o mestrado acadêmico e profissional. No MP todos os alunos concluíram apenas um curso de graduação, $44 \%$ têm mais de 10 anos de formado, apenas um não cursou a especialização, 28\% estudaram na mesma instituição onde estão realizando o mestrado e $40 \%$ são oriundos de instituição privada (Tabela 2).

Tabela 2 - Características da Formação dos Enfermeiros que Cursam o Mestrado em Enfermagem. Brasil, 2015. ( $\mathrm{N}=150)$

\begin{tabular}{|c|c|c|c|}
\hline \multicolumn{4}{|c|}{ FORMAÇÃO DOS PARTICIPANTES DA PESQUISA } \\
\hline \multicolumn{2}{|c|}{ Mestrado Acadêmico (MA) } & \multicolumn{2}{|c|}{ Mestrado Profissional (MP) } \\
\hline \multicolumn{2}{|c|}{ GRADUAÇÃO } & \multicolumn{2}{|c|}{ GRADUAÇÃO } \\
\hline \multicolumn{2}{|c|}{$\begin{array}{l}4 \text { alunos } 3 \% \text { tem mais de uma } \\
\text { graduação. }\end{array}$} & \multicolumn{2}{|c|}{ Todos têm apenas uma graduação. } \\
\hline \multicolumn{2}{|c|}{ TEMPO DE FORMAÇÃO } & \multicolumn{2}{|c|}{ TEMPO DE FORMAÇÃO } \\
\hline Últimos 5 anos & $81(64 \%)$ & Últimos 5 anos & $12(24 \%)$ \\
\hline $\begin{array}{l}\text { Últimos } 10 \\
\text { anos }\end{array}$ & $26(21 \%)$ & $\begin{array}{l}\text { Últimos } 10 \\
\text { anos }\end{array}$ & $16(32 \%)$ \\
\hline $\begin{array}{l}\text { Depois de } 10 \\
\text { anos }\end{array}$ & $19(15 \%)$ & $\begin{array}{c}\text { Depois de } 10 \\
\text { anos }\end{array}$ & $22(44 \%)$ \\
\hline \multicolumn{2}{|c|}{ ESPECIALIZAÇÃO } & \multicolumn{2}{|c|}{ ESPECIALIZAÇÃO } \\
\hline Nenhuma & Um ou mais & Nenhuma & Um ou mais \\
\hline $24(19 \%)$ & $102(81 \%)$ & $1(2 \%)$ & $49(98 \%)$ \\
\hline \multicolumn{2}{|c|}{ EGRESSOS } & \multicolumn{2}{|c|}{ EGRESSOS } \\
\hline $\begin{array}{l}\text { Mesma institu- } \\
\text { ição }\end{array}$ & $\begin{array}{l}\text { Instituição } \\
\text { privada }\end{array}$ & $\begin{array}{l}\text { Mesma institu- } \\
\text { ição }\end{array}$ & $\begin{array}{l}\text { Instituição } \\
\text { privada }\end{array}$ \\
\hline $69(55 \%)$ & $33(26 \%)$ & $14(28 \%)$ & $20(40 \%)$ \\
\hline \multicolumn{2}{|c|}{ Total: 126} & \multicolumn{2}{|c|}{ Total: 50} \\
\hline
\end{tabular}

No que diz respeito às atividades acadêmicas extracurriculares, os alunos do MA foram os que mais participaram - $21 \%$ de congresso, $16 \%$ de monitoria e outras modalidades de bolsa e $14 \%$ de grupo de pesquisa, projeto de extensão e estágio extracurricular. Já no MP a atividade mais freqüente foi congresso (31\%), sendo que as demais atividades não passaram de $14 \%$.

Em relação aos alunos do MA 70\% afirmaram que as atividades acadêmicas extracurriculares contribuíram muito ou totalmente para sua formação, enquanto que os alunos do MP ficaram divididos - metade deles disse que contribuiu muito ou totalmente e a outra afirma que contribuiu pouco ou nem um pouco. 
Vale, contudo, ressaltar, que os alunos do MA tiverem durante a graduação mais incentivo a participarem de atividades acadêmicas extracurriculares, com relevo as de iniciação científica que os alunos do MP e esse aspecto teve influencia direta na decisão de cursarem o mestrado.

\section{Características Empregatícias dos Alunos do Mestra- do em Enfermagem}

No que diz respeito ao emprego, verificou-se que $24 \%$ dos alunos do (MA) não trabalham. Dos que trabalham, $43 \%$ em ambiente hospitalar, 3\% em serviços de atenção básica, $20 \%$ no ensino e $10 \%$ exercem outras atividades. Já no (MP), todos trabalham, até mesmo porque esse é um critério para acesso aos programas de MP, 51\% trabalham em hospitais, 9\% em serviço de atenção básica, $30 \%$ no ensino e $10 \%$ exercem outras atividades.

Quanto ao vínculo empregatício verificou-se que 31\% dos alunos do (MA) trabalham com carteira assinada, $27 \%$ são concursados, $13 \%$ tem contrato temporário, $5 \%$ tem outros vínculos não informados e $24 \%$ não trabalham. No (MP) 67\% do alunos são concursados, $29 \%$ trabalham com carteira assinada, $2 \%$ têm contrato temporário e $2 \%$ tem outros vínculos não informado.

O salário mínimo no período da coleta era de 724,00 (setecentos e vinte quatro reais). No que se refere a renda, verificou-se que $28 \%$ dos alunos do (MA) ganham de 1 à 2 salários mínimos como enfermeiros, 33\% ganham de 3 à 5 salários mínimos, 22\% ganham de 5 à 8 salários mínimos e $9 \%$ ganham acima de 9 salários mínimos. Enquanto que os alunos do (MP) 4\% ganham até 2 salários mínimos como enfermeiro, 20\% ganham de 3 a 5 salários mínimos, $30 \%$ ganham de 5 a 8 salários mínimos e 36\% ganham acima de 9 salários mínimos.

\section{Motivação para Ingressar no Curso de Mestrado}

Verificou-se que $22 \%$ dos alunos do MA buscam qualificação para o ensino em enfermagem e formação teórica para a pesquisa, e $21 \%$ qualificação para o mercado de trabalho. No MP, 22\% buscam melhorar a atuação na atividade prática que exercem e $21 \%$ qualificação para o ensino de enfermagem.

Quanto à motivação para realizar o mestrado, os alunos do MA declaram: capacitação para pesquisa (91\%), ampliar conhecimento (87\%), valorização profissional através da cientificidade da profissão $(85 \%)$, desejo de ser docente e realizar o doutorado (85\%). Já os alunos do MP, ampliar conhecimento $(87 \%)$, aprimoramento prático $(86 \%)$, necessidade de melhorar a qualidade profissional (76\%) e valorização profissional através da cientificidade da profissão (74\%).
As motivações menos citadas foram: Prestígio social por $40 \%$ dos alunos do (MA) e $26 \%$ do (MP), Status por $44 \%$ dos alunos do (MA) e $30 \%$ do (MP) e recompensa financeira por $63 \%$ dos alunos do (MA) e $48 \%$ do (MP). Foi verificado quais são os incentivos para manter-se no mestrado e identificou-se que $72 \%$ dos alunos do (MA) e $88 \%$ dos alunos do (MP) utilizam recurso financeiros próprios. As bolsas de estudos são oferecidas apenas para alunos do (MA). Nesse estudo $27 \%$ dos alunos recebem esse incentivo. $\mathrm{O}$ convênio entre a instituição de trabalho e de ensino tem feito parte apenas dos programas de MP, porem apenas $8 \%$ dos alunos estudam por meio de convênio. O incentivo financeiro da instituição onde trabalham, tem contemplado apenas $1 \%$ dos alunos do (MA) e 4\% dos alunos do (MP).

O apoio emocional da família é o maior incentivo que os mestrando recebem para manter-se no mestrado, declarados por $54 \%$ dos participantes, apenas $22 \%$ recebe da instituição onde trabalha liberação de horário para estudo e $15 \%$ enfrenta dificuldade financeira ou social para manter-se no mestrado.

\section{DISCUSSÃO}

O estudo constatou que a presença de alunos do sexo feminino ainda é muito forte nos curso de enfermagem, ou seja, esta característica é um reflexo histórico da profissão que é exercida majoritariamente por mulheres (Camelo, Silva, Laus, e Chaves, 2013). Desta forma, a escolha do tipo de mestrado não está relacionada ao gênero dos alunos. Esse fato foi verificado através de teste do Qui-Quadrado com $(\mathrm{p})=0,808$.

Quanto a faixa etária da população estudada, os dados conferem com o perfil dos enfermeiros cadastrados no Conselho Federal de Enfermagem (COFEN), no qual a categoria apresenta a maior concentração de profissionais na faixa etária de 26 a 35 anos (COFEN, 2011). Os resultados estatísticos indicam que os alunos mais jovens ingressam em maior número no (MA), enquanto os mais velhos buscam o (MP). O comportamento analisado é comprovado pelo teste do Qui-Quadrado com $\mathrm{p}<0,05$.

No que se refere às características étnico-raciais dos mestrandos, utilizando-se a classificação usada pelo Instituto Brasileiro de Geografia e Estatística (IBGE), verificou-se que $43 \%$ dos alunos se declararam negros, pardos e indígenas, sendo que apenas $7 \%$ dos alunos são negros. 
A última pesquisa de características étnico-raciais da população realizada pelo IBGE constatou um aumento expressivo da parcela da população que espontaneamente declara a própria etnia como negra ou parda. $\mathrm{Ou}$ seja, nas últimas décadas houve uma maior valorização da negritude, refletida na mudança das declarações (IBGE, 2013). Tal valorização se fez retratar nas respostas dos mestrandos entrevistados quanto às questões relativas à declaração de raça.

No entanto, este resultado pode ser um reflexo do sistema de cotas, uma lei recentemente implementada nos processos seletivos para os cursos de graduação. A Lei $\mathrm{n}^{\circ} 12711 / 12$ garante a reserva de $50 \%$ das matrículas por curso e turno, nas 59 universidades federais e 38 institutos federais de educação, ciência e tecnologia. As vagas reservadas às cotas serão subdivididas, metade para estudantes de escolas públicas - com renda familiar bruta igual ou inferior a um salário mínimo e meio, e metade para estudantes da rede pública com renda familiar superior a um salário mínimo e meio. Os demais $50 \%$ das vagas permanecem para ampla concorrência (Lei no 12711/12).

A motivação do enfermeiro para cursar a pós-graduação stricto sensu pode começar por meio de uma inserção precoce dos graduandos em programas de iniciação científica, monitoria e projetos em grupo de pesquisa (Monteiro et al., 2012). E no presente estudo o teste Qui-Quadrado revelou significância na relação dos alunos cursarem o mestrado com o fato de terem realizado durante a graduação atividades acadêmicas como projeto de extensão e grupo de pesquisa, $\operatorname{com}(p)=0,0008$. A participação dos alunos nas atividades acadêmicas, ajuda-os a ter uma visão do curso de mestrado, ou seja o aluno não será desmotivado por pouco ou falta de conhecimento do curso, assim como terão conteúdos científicos que ajudaram na trajetória de construção de conhecimento durante o mestrado.

Os alunos que comentaram mais vezes sobre sua participação em atividades acadêmicas durante a graduação como uma colaboração parcial ou total para seu ingresso na pós-graduação stricto sensu, foram os alunos do mestrado acadêmico, e esses são oriundos de universidades públicas. As universidades públicas oferecem mais subsídios para que os alunos exerçam, durante o período da graduação, atividades de iniciação científica, enquanto que as universidades privadas nem sempre estabelecem esses parâmetros no conteúdo curricular, sendo os trabalhos de conclusão de curso (TCC), basicamente o único e último ensaio científico no curso de graduação (Ferreira, Tavares, Santos, e Fonseca, 2015).
As universidades públicas, muitas das vezes, além promover estímulos aos alunos às atividades acadêmicas de pesquisa durante a graduação, incentiva-os a realizar o mestrado como podemos observar nesse estudo, no qual verificou que é significativa a relação de ex-alunos realizando mestrado na instituição, conforme o resultado obtido no teste do Qui-Quadrado com $(\mathrm{p})=0,0011$. A UFF foi a instituição com maior número de mestrandos (MA e do MP) graduados na própria instituição, representando relevância estatística, quando aplicado o teste Qui-quadrado, onde $(\mathrm{p})=0,0369$. Este resultado relevante sob a ótica estatística mostra que a UFF é uma instituição diferenciada das demais citadas por este estudo. Uma das razões apontadas como origem e causa dos dados conclusivos é a existência do programa Altos Estudos, que promove a integração entre os cursos de graduação e a pós-graduação, acelerando e tornando viável a formação de alto nível.

O programa Altos Estudos possibilita que os estudantes experimentem o ambiente de pesquisa e pós-graduação inserindo-o no Curso de Mestrado durante a sua graduação; permitir a este estudante reduzir o tempo de conclusão da graduação e da pós-graduação stricto sensu, através de uma trajetória curricular avançada e integradora; contribuir para o desenvolvimento de competências gerais, específicas e transversais necessárias a sua formação e projeção profissional e como cidadão; propiciar a este aluno um ambiente estimulador que favoreça a manifestação de suas altas habilidades (UFF, 2014). Mostrou relevância com resultado do teste Qui-Quadrado com $(p)=0,0001$, a relação dos alunos do mestrado acadêmico serem mais jovens na profissão e terem uma renda mais baixa, assim como a relação dos alunos do mestrado profissional serem mais experientes e com uma renda maior.

Verificou-se que $28 \%$ dos alunos do (MA) ganham menos que o piso salarial, estabelecido pela lei n. ${ }^{\circ} 6983 / 15$, que instituiu o piso salarial no âmbito do estado do Rio de Janeiro, para a categoria de 2.432,72 (dois mil, quatrocentos e trinta e dois reias e setenta e dois centavos). Enquanto que apenas $4 \%$ dos alunos do (MP) ganham abaixo do piso (Lei no 6983/15). Bem como, verificou-se que $63 \%$ dos alunos do (MA) buscarem recompensa financeira.

Para Cunha, Junior, e Martins, (2010) o investimento na formação representa enorme valor para o próprio sujeito, para o mercado e para a comunidade, que retribuiriam com maior remuneração, mobilidade, diferenciação e estabilidade profissional, status, prestígio, respeitabilidade e reconhecimento, dentre outros. 
Porém no estudo esses não foram os principais fatores que motivam o enfermeiro a ingressar no mestrado. Apesar do valor que o profissional com título acadêmicos tem no mercado de trabalho, observou-se no estudo que há pouco incentivo das instituições empregatícias para os funcionários realizarem mestrado. A titulação é valorizada no processo seletivo para admissão do profissional, porém o incentivo para o funcionário fazer uma pós-graduação stricto sensu ainda não é comum no país, principalmente na área da enfermagem. As instituições que trabalham com prestação de serviços na área da saúde, tem como meta a produtividade, sendo seus investimentos focados em equipamentos modernos reforma de estrutura física, ou seja estão investindo em tecnologia (Bezerra, 2010), porem a Tecnologia é, também, "um conjunto de conhecimentos (científicos e empíricos) sistematizados, em constante processo de inovação, os quais são aplicados pelo profissional de enfermagem em seu processo de trabalho, para melhorar a qualidade de cuidado e a cientificidade da profissão (Koerich et al., 2006).

Ou seja, apesar de todo o reconhecimento do profissional com título de mestre, as instituições empregatícias não tem muita cultura de incentivo ao estudo, o que desmotiva os profissionais a estudar.

$\mathrm{O}$ que predominou dentre as motivações dos alunos para realizar o mestrado em enfermagem foi o desejo de ampliar o conhecimento, seja para capacitação para a pesquisa e exercer a docência dito pelos alunos do (MA) quanto para aprimorar a prática e a valorização profissional através da cientificidade da profissão dito pelos alunos do (MP).

A característica mais forte do mestrado profissional é a possibilidade de aproximar a pesquisa do exercício profissional. O curso é dirigido à capacitação de profissionais mediante o estudo de técnicas, processos, ou temáticas por meio da incorporação do método científico, habilitando o profissional para atuar em atividades técnico-científicas e de inovação que atendam aos avanços da profissão (Tavares e Silva, 2014). Tal ênfase nos estudos e técnicas, diretamente voltadas ao desempenho de um alto nível de qualificação profissional, é a única diferença em relação ao acadêmico (Coordenação de Aperfeiçoamento de Pessoal de Nível Superior, 2015).

\section{CONCLUSÃO}

O perfil dos alunos do MA e do MP é bem distinto. Os alunos mais jovens de idade e de profissão optam pelo mestrado acadêmico, enquanto o oposto opta pelo mestrado profissional.

A principal motivação dos enfermeiros cursarem o mestrado foi a busca por novos conhecimentos, seja para o aprimoramento da prática dos alunos do (MP), ou para qualificá-los para a docência, quando se trata de alunos do (MA).

Essa motivação vem desde a graduação, quando projetos de pesquisa proporcionam a inserção de alunos, como bolsistas, em pesquisas de extensão ou de iniciação científica, também pode ser por desenvolvimento de atividades como monitorias, sem esquecer o trabalho final de curso, mas conhecido como TCC, entre esses e outros encorajamentos à pesquisa que encontramos a motivação para o ingresso ao programa stricto sensu. Os enfermeiros que tiveram mais incentivos durante a graduação para a realização de atividades extracurriculares optaram pelo mestrado acadêmico, almejando inclusive realizar o doutorado na sequência do mestrado, enquanto que os alunos que tiveram uma trajetória profissional dedicada à prática profissional optam pelo mestrado profissional. Constata-se assim que os interesses dos alunos vão ao encontro das propostas de cada curso.

Este estudo apontou o perfil dos alunos de mestrado acadêmico e profissional do estado do Rio de Janeiro, e suas motivações para realizar o mestrado. Porém, as instituições coparticipantes foram da esfera pública, o que caracteriza uma limitação desta pesquisa, por sua vez, esta limitação possibilita novas pesquisa sobre esta temática, entretanto, com uma nova lente crítica que envolva as instituições da rede privada, o que permitirá a produção de novos conhecimentos.

\section{IMPLICAÇÕES PARA A PRÁTICA CLÍNICA}

O curso de mestrado tem contribuído para a formação de enfermeiros mais críticos e reflexivos, que buscam no curso soluções para os problemas relacionados à prática profissional, como é o caso dos alunos do mestrado profissional, assim como qualificação para a docência, como é o caso dos alunos do mestrado acadêmico. Todo o conhecimento construído no mestrado implica em uma prática assistencial e educacional qualificada e cientificizada. 


\section{REFERÊNCIAS BIBLIOGRÁFICAS}

Bezerra, F. D., Andrade, M. F. C., Andrade, J. S., Vieira, M. J., e Pimentel, D. (2010). Motivação da equipe e estratégias motivacionais adotadas pelo enfermeiro. Revista Brasileira de Enfermagem, 63(1), 33-37. Disponível em http://www.scielo.br/scielo.php?script=sci_arttext\&pid $=$ S0034-71672010000100006

Camelo, S. H. H., Silva, V. L. S., Laus, A. M., e Chaves, L. D. P. (2013). Perfil profissional de enfermeiros atuantes em unidades de terapia intensiva de um hospital de ensino. Ciencia y Enfermería, 19(3), 51-62. Disponível em http://www.scielo.cl/scielo.php?script=sci arttext\&pid=S0717-95532013000300006\&lng=pt\&nrm $=$ iso\&tlng $=\mathrm{pt}$

Conselho Federal De Enfermagem. (2011). Análise de dados das inscrições dos profissionais de enfermagem existentes nos conselhos regionais no ano de 2011. Disponível em http://www.portalcofen.gov.br/atlas/

Coordenação de Aperfeiçoamento de Pessoal de Nível Superior. (2015). Qual é a diferença entre o mestrado acadêmico e o mestrado profissional?. Disponível em http://www.capes.gov.br/acessoainformacao/perguntas-frequentes/avaliacao-da-pos-graduacao/7419-mestrado-profissional

Cunha, J. V. A., Junior, E. B. C., e Martins, G. A. (2010). Doutores em ciências contábeis: Análise sob a óptica da Teoria do Capital Humano. Revista de Administração Contemporânea, 14 (3), 532-557. Disponível em http://www.scielo.br/scielo.php?script=sci_arttext\&pid $=$ S1415-65552010000300009

Erdmann, A. L., Fernandes, J. D., e Teixeira, G. A. (2011). Panorama da educação em enfermagem no Brasil: Graduação e pós-graduação. Enfermagem em Foco, 2(supl), 89-93. Disponível em http://revista.portalcofen. gov.br/index.php/enfermagem/article/view/91

Ferreira, R. E., e Tavares, C. M. M. (2015). A motivação do enfermeiro para a realização do mestrado e sua relação com o desenvolvimento profissional (Dissertação de Mestrado), Escola de Enfermagem Aurora Afonso Costa da Universidade Federal Fluminense, Rio de Janeiro, Brasil.
Ferreira. R. E., Tavares, C. M. M., Santos, G. S., e Fonseca, P. I. N. M. (2015). Motivação do enfermeiro para ingressar em uma pós-graduação stricto sensu. Revista Baiana de Enfermagem, 29(2), 180-185. Disponível em http://www.portalseer.ufba.br/index.php/enfermagem/ article/view/10738

Instituto Brasileiro de Geografia e Estatística. (2013). Características étnico-raciais da população - classificações e identidades. Rio de Janeiro: Estudos e Análises - Informação Demográfica e Socioeconômica.

Koerich, M. S., Backes, D. S., Scortegagna, H. M., Wall, M. L., Veronese, A. M., Zeferino, M. T., ...Santos, E. K. A. (2006). Tecnologias de cuidado em saúde e enfermagem e suas perspectivas filosóficas. Texto \& Contexto Enfermagem, 15(Esp), 178-185. Disponível em http:// www.scielo.br/pdf/tce/v15nspe/v15nspea22

Lei no 9394/96. Lei de Diretrizes e Bases da Educação Nacional. Art. 44, III. Disponível em https://www.ufpe. br/ctg/images/lein9394.pdf

Lei $n^{\circ} 12711 / 12$. Lei de Cotas para o Ensino Superior. Disponível em http://portal.mec.gov.br/cotas/perguntas-frequentes.html

Lei $n^{\circ}$ 6983/15. Lei do Estado do Rio de Janeiro. Art. 1, VII. Disponível em http://www.rj.gov.br/web/setrab/ exibeconteudo?article-id=244747

Monteiro, E. M. L. M., Moraes, M. U. B., Brandão, N. W., Aquino, J. M., Gregório, V. R. N., e Mishima, S. M. (2012). Programa de pós-graduação stricto sensu em enfermagem: Opinião de graduandos. Revista de Pesquisa: Cuidado é Fundamental, 4(1), 2758-2769. doi: dx.doi.org/10.9789/2175-5361

Parecer no 977/65. Definição dos Cursos de Pós-Graduação. C. E. Su, Aprovado em 1965-12-03.

Scochi, C. G. S., Munari, D. B., Gelbcke, F. L., Erdmann, A. L., Gutiérrez, M. G. R., e Rodrigues, R. A. P. (2013). Pós-graduação Stricto Sensu em enfermagem no Brasil: Avanços e perspectivas. Revista Brasileira de Enfermagem, 66(esp), 80-89. Disponível em http:// www.scielo.br/scielo.php?script $=$ sci_arttext \&pid $=$ S0034-71672013000700011 
Silvino, Z. R. (2013). Ten years of Professional Master Degree in Nursing Care of Fluminense Federal University. Online Brazilian Journal of Nursing, 12 (Supl), 574577. Disponível em http://www.objnursing.uff.br/index. php/nursing/article/view/4583
Tavares, C. M. M., e Silva, R. M. C. R. A. (2014). Real interdisciplinary possibilities in the context of professional master's degree course. Online Brazilian Journal of Nursing, 13, 362-365. Disponível em http://www.objnursing.uff.br/index.php/nursing/article/view/5073

Universidade Federal Fluminense. (2014). Edital de Seleção do Programa Altos Estudos. 